\title{
Juízo, imaginação e mentalidade alargada: a interpretação arendtiana do juízo estético kantiano
}

\author{
Judgment, imagination and enlarged mentality: the arendtian \\ interpretation of the kantian aesthetic judgment
}

\begin{abstract}
Adriano Correia
Professor adjunto em Filosofia da Universidade Federal de Goiás (UFG), pesquisador do CNPq, nível 2, Goiânia, G0 - Brasil, e-mail: correiaadriano@yahoo.com.br
\end{abstract}

\section{Resumo}

Pretendo apresentar, neste artigo, alguns dos conceitos kantianos na Crítica da faculdade do juízo apropriados na análise política arendtiana do juízo estético kantiano: juízo, imaginação, mentalidade alargada, senso comum. A despeito das dificuldades resultantes do caráter inacabado da abordagem arendtiana da vida do espírito, buscamos explicitar que ela encontra, na obra kantiana, os elementos básicos de sua análise da atividade mental do juízo. Ela sustenta não apenas que o juízo reflexionante estético pode ser apropriado politicamente, mas que na Crítica da faculdade do juízo encontra-se a filosofia política oculta da obra kantiana. A tal posição polêmica iremos apenas aludir, analisando os conceitos de pensamento crítico e mentalidade alargada.

Palavras-chave: Juízo. Imaginação. Mentalidade alargada. Senso comum. 


\section{Abstract}

In this paper I intend to present some of the Kantian concepts presented in his Critique of judgment and appropriated by Hannah Arendt in her political analysis of the Kantian aesthetic judgment: judgment, imagination, enlarged mentality, common sense. Despite the difficulties arising from the unfinished character of Arendt's approach on the life of spirit, we attempt to expose that she finds, within Kant's works, the basic elements of her analysis of the mental activity of judging. She not only argues that the reflective aesthetic judgment might be politically adopted, but also that in the hidden political philosophy of Kantian work lies in the Critique of Judgment. To this controversial position I am only goin to refer to by analyzing the concepts of critical thinking and enlarged mentality.

Keywords: Judgment. Imagination. Enlarged mentality. Common sense.

Embora não tenhamos os metros para medir e as regras sob as quais podemos subsumir o particular, um ser cuja essência é o começo pode trazer dentro de si um teor suficiente de origem para compreender sem categorias preconcebidas e para julgar sem esse conjunto de regras comuns que é a moralidade (ARENDT, 1993a, p. 52).

Na primeira vez em que Hannah Arendt ministrou um curso sobre a filosofia política de Kant, em 1955, ela ainda não lidava com a questão do juízo, mesmo já tendo aparecido no ensaio "Compreensão e política" (1953), no conceito de compreensão, vários traços da sua posterior caracterização do juízo e da imaginação. Ademais, ela lida nesse curso com a teoria política de Kant considerando o entendimento que ele tem da vontade, fundamentalmente na reflexão sobre a moral, algo que mais tarde ela abandonará por completo - a compreensão tanto da ação política quanto da atividade espiritual da vontade via moralidade -, não só por julgar que o próprio Kant sabia não ser de valia imediata a sua filosofia moral na organização do Estado, mas também por se dar conta de que "o juízo do particular - isso é belo, isso é feio; isso é certo, isso é errado - não tem lugar na filosofia moral kantiana" (ARENDT, 1993b, p. 22-25). Apenas dois anos mais tarde aparece mencionada a Crítica da faculdade do juízo, em uma carta a Jaspers datada de 29 de agosto de 1957, já no sentido que a ocupará doravante até sua morte. 
No momento - diz ela - estou lendo a Crítica da faculdade do juízo com crescente satisfação. Lá, e não na Crítica da razão prática, é onde está oculta a verdadeira filosofia política de Kant. Sua exaltação do 'senso comum', tão frequentemente desprezado; o fenômeno do gosto tomado seriamente como o fenômeno básico do juízo [...]; o 'modo expandido de pensamento', que é uma parte essencial do juízo, de maneira que se possa pensar do ponto de vista qualquer outra pessoa. A exigência de comunicabilidade. Isso incorpora as experiências que o jovem Kant teve em sociedade e que então o homem idoso reavivou novamente (ARENDT, 1993c, p. 318).

Na mesma correspondência, ela menciona estar terminando A condição humana (1958) e começando a trabalhar no texto de uma introdução à política com o qual ela se comprometeu junto a um editor alemão (Piper). Em um texto chamado "Preconceito e juízo", uma tentativa de levar adiante esse projeto que nunca chegou a concluir, ela retoma a sua reflexão sobre compreensão preliminar e verdadeira compreensão, tal como aparece em "Compreensão e Política", e encaminha uma reflexão sobre o julgar que já estabelece um diálogo intenso com Kant. Assim como a compreensão preliminar poupa o homem de tentar compreender a cada momento mesmo a situação mais banal, os preconceitos que compartilhamos com os outros, e sobre os quais podemos discorrer sem grande esforço explicativo, nos pouparia do sobre-humano estado de alerta que seria requerido se tivéssemos de julgar a cada momento tudo o que se passa. Em vista disso, os preconceitos, que em alguma medida remontariam sempre à experiência pessoal, embora envolvam sempre o risco de ocupar de fato o lugar do juízo e bloqueá-lo, permite uma compreensão preliminar do que se nos apresenta. Desse modo, ainda que na política nos orientemos de fato por juízos e busquemos sempre dissipar preconceitos pela reflexão, tais preconceitos são indispensáveis à condução na vida social normal e, em certa medida, indissolúveis em sua totalidade.

Nesse texto, Hannah Arendt chama a atenção para dois sentidos do juízo: por um lado, a subordinação do particular, segundo critérios, a algo geral e universal, muitas vezes partindo de nossos preconceitos; por outro, a avaliação de eventos e objetos para os quais não dispomos 
de critérios, pela própria natureza de tais eventos e objetos ou por representarem algo com que nunca havíamos travado contato antes. Esse segundo modo de julgar, que ela já diz ser análogo ao juízo estético tal como aparece em Kant,

não tem parâmetro, não pode recorrer a coisa alguma senão à própria evidência do julgado, não possui nenhum outro pressuposto que não a capacidade humana do discernimento, e tem muito mais a ver com a capacidade de diferenciar do que com a capacidade de ordenar e subordinar (ARENDT, 1998, p. 31-32).

Também já aqui ela menciona essa capacidade como fundamental à orientação em um mundo legado sem testamentos: "a perda de critérios [...] só é uma catástrofe no mundo moral quando se supõe que os homens não estão em condições de julgar a própria coisa, que sua capacidade de discernimento não basta para um julgar original" (ARENDT, 1998, p. 34).

A referência de Hannah Arendt a Kant e à Crítica da faculdade do juízo já em "A crise da cultura" (1961), recolhido em Entre o passado e o futuro, não é, portanto, incidental. A parte final do texto é dedicada justamente ao exame das possíveis relações entre estética e política, entre gosto e juízo. Quando Arendt examina a relação entre o belo e a pólis, na qual o domínio político determinava os limites do amor à sabedoria e à beleza, afirma que a distinção fundamental entre os bárbaros e os gregos residia não no amor à beleza, mas no modo como se relacionavam com os objetos da cultura: estes últimos amavam ativamente a beleza, mas não de um modo indiscriminado e sim com uma precisão de mira, segundo determinados parâmetros. Esse reto amor pela beleza, essa discriminação do que é belo, diz ela, pode ter algo a ver com a política. Embora Kant concorde com os filósofos clássicos com relação à valoração depreciativa da vida, ao menos na relação entre a quantidade de prazer e de desprazer, não se pode dizer o mesmo dele com respeito ao corpo e aos sentidos. Kant sustenta, em contraposição direta a Platão, por exemplo, "que todo conhecimento depende da interação e cooperação entre sensibilidade e intelecto", de forma que o corpo não se torna um limite, mas um aliado do intelecto. A principal 
consequência disto, para o filósofo, é que ele passa, em primeiro lugar, a ser tido como alguém que clarifica as experiências tidas por todos e que por isto mesmo não deve viver entre os filósofos ou isolado do mundo, mas entre seus pares; em segundo lugar, defende que não é exclusividade do filósofo "avaliar a vida com relação ao prazer e ao desprazer” (ARENDT, 1995, p. 38-39), pois tal juízo pode ser levado a cabo por qualquer pessoa de bom senso.

$\mathrm{Na}$ resposta de Jaspers à carta anteriormente citada, ele convida Hannah Arendt para um seminário em que trabalhariam juntos a Crítica da faculdade do juízo. Isto não veio a se concretizar, mas em 1964, na Universidade de Chicago, Arendt ministrou um curso sobre a filosofia política de Kant com base na terceira crítica, já pressupondo que ele não escreveu uma filosofia política nem que é fundamental à obra kantiana o que é tido como sua filosofia política - os escritos sobre a história, a teoria e a prática, a paz perpétua, a doutrina do direito, etc.; pressupunha ainda que se há alguma filosofia política oculta em Kant, ela deve ser buscada não nesses escritos e nem mesmo na Crítica $d a$ razão prática, mas na terceira crítica. Esse curso fora a base para outro curso, ministrado em 1970 na New School for Social Research e editado em 1982 por Ronald Beiner com o nome de Lições sobre a filosofia política de Kant. Hannah Arendt refere-se a uma filosofia política apenas oculta em Kant não só por ele não ter escrito uma filosofia política, mas também porque dentre as questões que fazem o homem filosofar, mencionadas por ele - O que posso conhecer? O que devo fazer? O que posso esperar? -, nenhuma "sequer menciona a condição da pluralidade humana” (ARENDT, 1993b, p. 29). Por razão análoga, ela diz não se interessar pelo juízo teleológico, por ele, em última instância, ocupar-se da natureza, ou da história como parte dela, e não do particular em sentido estrito. Em todas essas perguntas fundamentais o que estaria em questão é o interesse próprio, ou na própria felicidade (ou no tornar-se digno dela) e não o interesse pelo mundo. De qualquer modo, Hannah Arendt julgava que Kant não precisava escrever uma filosofia política, ou ao menos não precisava se ocupar dela com a preocupação tradicional daquele filósofo que quer evitar ser governado pelos que navegam no navio dos alienados, pois não apenas julgava que o pensar 
e mesmo a avaliação do mundo em geral, assim como o saber o que é bom para si, é atributo de toda pessoa sã, como também sustentava que "o filósofo permanece um homem como vocês e eu, vivendo entre seus companheiros e não entre filósofos” (ARENDT, 1993b, p. 38-39). Não opondo a maioria à minoria e assumindo o filosofar como uma "necessidade da razão enquanto faculdade humana", Kant faz desaparecer em seu próprio pensamento a tensão entre a filosofia e a política e "o resultado é que a política e a necessidade de escrever uma filosofia política, a fim de estabelecer leis para um 'asilo insano', deixam de ser uma preocupação urgente para o filósofo" (ARENDT, 1993b, p. 40).

O prazer estético, tal como considerado por Kant, situa-se conceitualmente entre um prazer sensível e um prazer racional e é precisamente essa posição intermediária que sugere que a estética possui uma função mediadora entre natureza e liberdade e entre sensibilidade e razão (prática) pura. O prazer estético seria o elemento derivado da atividade reflexivo-produtiva cuja tarefa é a procura de uma universalidade possível, mas não disponível. Assim,

no caso de se ajuizar a forma do objeto (não o objeto da sua representação, como sensação) na simples reflexão sobre a mesma (sem ter a intenção de objeto um conceito dele), como o fundamento de um prazer na representação de tal objeto, então nesta mesma representação este prazer é julgado como estando necessariamente ligado à representação, por consequência, não simplesmente para o sujeito que apreende esta forma, mas sim para todo aquele que julga em geral. O objeto chama-se então belo e a faculdade de julgar mediante tal prazer (por conseguinte também universalmente válido) chama-se gosto (KANT, 1993, p. 34 [Intr. XLV], grifos nossos).

Lidamos, por um lado, com um sentimento de prazer que, mesmo sendo subjetivo, se realiza como passível de ser conhecido somente por meio da percepção refletida do objeto e ligada a ela. Por outro lado, com um sentimento de prazer que é, por si só, por sua própria existência, um testemunho ou um índice da conformidade a fins de um dado objeto ajuizado pela faculdade de julgar reflexiva. Além disso, ainda que não possa expressar qualquer validade objetiva ou mesmo exigir 
uma validade a priori como os juízos empíricos, o juízo de gosto exige um reconhecimento da sua validade por toda a gente, pois, uma vez apoiado no sentimento de prazer, pode vincular a adequação do objeto à sua representação de modo análogo à ligação de um predicado ao conhecimento do objeto. Tal "universalidade" é requerida ainda porque o fundamento do prazer se encontra assentado na representação formal do objeto, não se relacionando diretamente, portanto, nem com uma sensação dele, nem com um conceito que contenha qualquer intenção em relação a ele. Uma vez que nenhum conceito do objeto vem a ser fundamento do juízo, "ele somente pode consistir na subsunção da própria faculdade da imaginação (em uma representação pela qual um objeto é dado) à condição de que o entendimento em geral chegue da intuição a conceitos" (KANT, 1993, p. 133 [§ 35, 146]). A representação do objeto na reflexão concorda, desse modo, somente com a "legalidade no uso empírico na faculdade do juízo em geral (unidade da faculdade da imaginação com o entendimento) no sujeito... As condições dessa reflexão são válidas a priori de forma universal" (KANT, 1993, p. 34 [Intr., XLV]) ${ }^{1}$. Isto explica porque os juízos de gosto, na medida em que a sua possibilidade pressupõe um princípio a priori, também estão sujeitos a uma crítica, mesmo tal princípio não sendo um princípio de conhecimento para o entendimento nem um princípio prático para a vontade, isto é, de nenhum modo determinante a priori.

Kant se detém mais na ideia de um sentido comum quando trata do juízo de gosto segundo a modalidade da complacência do objeto. Ele observa que se pensa do belo que ele tenha uma referência necessária à complacência, sendo que essa necessidade não é nem objetiva teórica, por meio da qual eu já teria uma determinação a priori do que é ou não belo, nem uma necessidade prática, consoante a qual a complacência seria uma consequência necessária de uma lei objetiva, mediante conceitos de uma vontade racional pura. Essa necessidade só

Mais adiante, Kant afirma que o prazer é o fundamento da determinação do juízo de gosto "somente pelo fato de estarmos conscientes de que assenta simplesmente na reflexão e nas condições universais, ainda que subjetivas, do seu acordo com o conhecimento dos objetos em geral, para os quais a forma do objeto é conforme a fins" (KANT, I. Crítica da faculdade do juízo. Tradução de Valerio Rohden e António Marques. Rio de Janeiro: Forense Universitária, 1993. p. 35 [Intr. XLVII]). Conferir ainda 0 § 6: "0 belo é 0 que é representado sem conceitos como objeto de uma complacência universal". 
pode ser exemplar, isto é, "uma necessidade do assentimento de todos a um juízo que é considerado como exemplo de uma regra universal que não se pode indicar" (KANT, 1993, p. 82 [§ 18, 163]). O dever que já se encontra aderido à imputação do assentimento a qualquer um pelo sujeito que julga, por sua vez, só pode ser expresso condicionalmente. Esse assentimento, ademais, só é suposto em cada um porque para isso o juízo se apoia em um fundamento que é comum a todos.

Partindo do problema da unidade da experiência, Kant descobre, por meio do juízo, o sentimento de prazer e desprazer, cuja incorporação sistemática no corpo da filosofia transcendental não deixará de ser problemática. Este "mistério" do princípio do juízo consiste no harmonioso agir em conjunto dos poderes da mente, num jogo subjetivamente necessário, involuntário, mas não casual, a indicar uma harmonia do homem com o mundo. Esta disposição à afinidade seria um momento orientador no progresso das ciências e um estímulo à práxis em geral. Essa afinidade expressa no juízo descreveria uma satisfação do sujeito cognoscente diante da sua capacidade de compreensão dos objetos belos mesmo diante da resistência deles à mera subsunção. Esse tipo de compreensão seria prazeroso já por insinuar uma predisposição da natureza, da sua estruturação como um sistema compreensível ao entendimento. A relação tida por Kant como necessária entre sentimento de prazer e o juízo reflexivo é expressa de dois modos: de um lado, sempre sentimos prazer quando aplicamos com algum progresso o juízo à multiplicidade dos objetos do conhecimento; de outro, também sentimos prazer pelo fato de, na condição de sujeitos reflexivos da ação, podermos vivenciar no exercício do juízo a organização final das nossas próprias faculdades de conhecimento. O juízo reflexivo, antes de articular as subjetividades nos julgamentos que cobram universalidade por referência ao senso comum, articula os diversos poderes da mente do sujeito - imaginação e entendimento - entre si mesmos. Nos dois momentos, embora alie a isto uma promessa de preenchimento da lacuna entre a teoria e a prática, o juízo reflexivo refere-se primordialmente ao sujeito reflexivo e à sua própria capacidade de conhecer e se comunicar de forma não idiossincrática.

Embora se refira primordialmente ao sujeito, o juízo estético reclama gozar de universalidade sem pretensão de ser objetivo e sem se 
legitimar pela adesão que a rigor pede a cada um; pretende determinar "seu objeto com respeito à complacência (como beleza) com uma pretensão de assentimento de qualquer um, como se fosse objetivo" (KANT, 1993, p. 128 [§ 32, 136]), pois jamais "o que aprouve aos outros pode servir como fundamento de um juízo estético" e nem mesmo regras determinadas podem determinar o juízo sobre a beleza (KANT, 1993, p. 130-131 [§ 33, 140-141]). Com efeito, o fundamento determinante do juízo de gosto é a complacência julgada comunicável universalmente sem conceito, decorrente da relação das faculdades de representação na determinação de um objeto, "declarada pelo juízo de gosto como válida para todos” (KANT, 1993, p. 67 [§ 11, 35]).

Aqui se trata de ver que no juízo de gosto nada é postulado, a não ser uma voz universal com vistas à complacência, sem mediação dos conceitos; por conseguinte, a possibilidade de um juízo estético que, ao mesmo tempo possa ser considerado válido para qualquer um. O próprio juízo de gosto não postula o acordo unânime de qualquer um... ele somente imputa [es sinnt an] a qualquer um este acordo como um caso de regra, com vistas ao qual espera a confirmação não de conceitos, mas da adesão de outros. A voz universal é, portanto, somente uma ideia (KANT, 1993 , p. $60[\S 8,25-26])$.

A universalidade subjetiva pretendida pelo juízo de gosto não faz uma referência direta à intersubjetividade como momento do próprio juízo, mas somente faz referência a todos os outros na medida em que os imputa a cada um o dever de dar seu assentimento. Não há a expectativa de um acordo, pois este é como que pressuposto, de modo que o juízo de gosto requer somente o reconhecimento da sua pretensão de universalidade. E se houver um conflito entre a comunidade ideal e a comunidade real daqueles que julgam, a primeira prevalecerá inevitavelmente sobre a segunda, pois, a rigor, embora se apele à comunidade, que é como o domínio específico do juízo estético, ela permanece irrealizável (LEBRUN, 1993, p. 493-494). A comunidade do juízo estético de Kant, internamente determinada pelo sensus communis, assume o "acordo" como pressuposto, isto é, não como telos de um processo de comunicação livre de coerções, mas como condição 
de possibilidade da comunicabilidade universal dos juízos de gosto e, consequentemente, também condição fundamental da pretensão de que a concordância com os juízos de gosto venha a se constituir como um dever. Se Kant sugeriu algum tipo de acordo implícito, foi somente o que se dá em nossas faculdades, cujo exemplo talvez mais essencial possa ser encontrado no gosto estético. A universalidade subjetiva não é a universalização do sentimento subjetivo empírico de prazer, mas do prazer desinteressado experimentado por todo aquele que julga, na medida em que está autorizado a pressupor em cada homem as mesmas condições subjetivas da faculdade do juízo que encontra nele (KANT, 1993, p. 137 [§ 38, Obs., 152]). O juízo precede o prazer. De fato, "nós só podemos compreender e comunicar a outros aquilo que efetuamos, pressupondo que podemos admitir como idêntico em todos o modo pelo qual intuímos algo para fazer disto ou daquilo uma representação" (KANT, Carta a Beck 01/07/1794, apud LEBRUN, p. 495).

Tão significativa quanto a universalidade subjetiva do juízo de gosto, notadamente para a apropriação arendtiano, é a sua condição imparcial. Conquanto possamos admitir que as experiências pessoais, desejos e várias outras determinações subjetivas jogam importante papel no contato com uma obra de arte, por exemplo, devemos simultaneamente assinalar que o mesmo não deve se dar no caso do juízo puro de gosto. A questão da beleza de uma determinada obra não pode ser, por assim dizer, contaminada por nenhum interesse na existência do objeto, pois um juízo estético deve ser completamente imparcial (KANT, 1993, p. 49-50 [§ 2]). Quando me indago acerca da beleza de um objeto não pergunto sobre a dependência de algo da existência de uma coisa, mas somente julgo por meio da mera observação intuitiva ou reflexiva; só julgo o que faço em mim mesmo da representação derivada. Desse modo me encontro desde o início, tal como indicado pela satisfação pura desinteressada do juízo de gosto, na condição de espectador, de quem julga as coisas sem se deixar determinar pela existência delas. Isto é o que permite à experiência estética, em oposição ao extremo subjetivismo e ao ceticismo, possuir uma dimensão comunicativa intrínseca, pois, na medida em que, na experiência estética, a imaginação age em conjunto com o entendimento, tal experiência não 
consiste em meras fantasias privadas, mas em pensamentos controlados e comunicáveis.

Embora não careça de uma comunidade real para que faça sentido, "o juízo estético só pode ser reflexivo entre os homens", pois a reflexão, no caso do juízo estético, é a pretensão de ter julgado por todos, de ter superado o sentimento meramente privado. O juízo de gosto ensina, fundamentalmente, a levar os outros em consideração no juízo, mesmo julgando sem eles e mesmo contra eles, pois não se julga sem a ideia do outro: "é essa Ideia, e não meu sentimento, que prevalece sobre a opinião dos outros de fato". De qualquer modo, "o sujeito reflexionante descobre que o reconhecimento ideal por outros 'si mesmos' é o único meio que lhe resta para atestar seu direito" de falar em nome de todos (LEBRUN, 1993, p. 488-490). Em cada momento, estamos diante da reafirmação da posição do espectador, que, embora espere dos outros a outorga do direito de falar em nome de todos, não carece deles de fato na operação de reflexão que realiza na formulação do juízo; no fim das contas, o espectador, em sua solidão, espera escapar da idiossincrasia e do solipsismo do seu juízo puramente subjetivo, colocando-se na companhia de espectros com os quais ele se solidariza e aos quais ele considera enquanto julga. De um lado, portanto, a imaginação permite que tenha presente o que está ausente, que torne em representação um objeto removido da percepção sensível imediata de quem julga; de outro, uma vez removidos dos sentidos externos, torna-se uma representação que é objeto para os sentidos internos e se presta à operação de reflexão, quando o gosto se detém sobre a representação e a julga - aprova ou desaprova algo em seu próprio valor (ARENDT, 1993b, p. 85-89).

As razões pelas quais Hannah Arendt se ocupa do juízo reflexivo estético kantiano como afim à política são fundamentalmente as seguintes: ele lida com o particular enquanto particular e sempre pressupõe a presença dos outros. Quando julgo, julgo sempre como membro de uma comunidade (ARENDT, 1993b, p. 93). Se o gosto é uma espécie de sensus communis, ou senso comunitário, como queria Kant, quando profiro juízos estéticos, tenho sempre em mente a presença dos outros. Ademais, ainda que a finalidade opere como ideia reguladora em nossos juízos, "a ausência de fim dos objetos de arte, tanto quanto a 
aparente ausência de fim da variedade da natureza, têm o 'fim' de agradar os homens, de fazê-los sentir-se em casa no mundo" (ARENDT, 1993b, p. 98). A beleza não é apenas a fulguração da imperecibilidade do mundo, mas também a forma mais elevada de satisfação nesse mundo. Como afirmou Kant, "o fato de o homem ser afetado pela pura beleza da natureza prova que ele foi feito e moldado para este mundo" (KANT, "Reflexionen zur Logik" apud ARENDT, 2003b, p. 41). Do mesmo modo, pode-se afirmar que o próprio fato de que ele é capaz de julgar de um ponto de vista geral indica que ele é moldado para estar não apenas junto a si, mas também junto aos outros.

Em Kant, tanto o pensar quanto o julgar operam sob a exigência de comunicabilidade, ao ponto de identificar a liberdade política com o uso público da razão, com a liberdade para falar e publicar: a própria atividade do pensamento depende do seu uso público, pois nenhum pensamento poderia se constituir sem o "teste do exame livre e aberto". Embora o pensamento, por fim, consista em uma ocupação solitária, a faculdade de pensar, "exercida em plena solidão, deixará de existir a não ser que possamos de alguma maneira comunicar e expor ao teste dos outros, oralmente ou por escrito, o que quer que tenhamos descoberto quando estávamos a sós" (ARENDT, 1993b, p. 52-53). O pensamento crítico exige comunicabilidade, depende dos outros para ser possível; e tal comunicabilidade implica e exige uma comunidade de homens a que se possa endereçar. É nesse contexto que surge a necessidade e o imperativo da comunicabilidade geral que Kant exigia dos juízos de gosto. É importante notar que, sem a imaginação, ficamos incapacitados de julgar também por sermos incapazes de nos comunicar com os outros - de emitir juízos, mas também de reconhecer os juízos dos outros.

Em Kant, o próprio filosofar é tido como necessidade da razão em geral e dessa forma ele faz desaparecer a hierarquia tradicional entre os modos de vida, e acompanhado dela vai-se a preocupação urgente e temerosa do filósofo para com a política, pois este, compartilhando com todos a razão e as suas implicações, não tem mais por que temer ter sua vida governada por um político que, enquanto tal, tenderia a ser estulto. Nas palavras de Hannah Arendt, "o resultado é que a política e 
a necessidade de escrever uma filosofia política, a fim de estabelecer leis para um 'asilo insano', deixam de ser uma preocupação urgente para o filósofo" (ARENDT, 1995, p. 40). À filosofia resta fundamentalmente o exercício público da crítica. A maiêutica socrática teria realizado justamente a transição do objeto de preocupação da filosofia dos céus para o âmbito da opinião dos homens, que passou então a ser examinado em suas condições e implicações latentes. O pensamento crítico, tal como aparece em Kant, também consiste nesse exame das implicações das afirmações, e como tal supõe a disposição geral de cada um a prestar contas do que diz, a se responsabilizar pelo que pensa e prega, assim como pelas iniciativas que toma. A arte do pensamento crítico, por seu turno, não é apreendida no simples movimento de análise das tradições e doutrinas que herdamos, "mas precisamente aplicando padrões críticos ao próprio pensamento" (ARENDT, 1993b, p. 56). Esse movimento autorreflexivo, por sua vez, supõe publicidade, prevê a possibilidade de interação com o pensamento dos outros, por um lado, e a consideração dos pontos de vista dos outros, por outro, conditio sine qua non da imparcialidade. Em Kant, tal imparcialidade é expressa no conceito de "mentalidade alargada" ou "alargamento do espírito", que consiste no movimento de consideração do pensamento dos outros, pelo uso da imaginação, por meio da comparação de nossos juízos com os juízos possíveis, e nesse sentido corresponde à capacidade de pensar representativamente. Assim, do pensamento crítico podemos afirmar, segundo H. Arendt, que "certamente ele ainda se dá em isolamento, mas, pela força da imaginação, torna presentes os outros e, assim, move-se em um espaço potencialmente público, aberto a todos os lados" (ARENDT, 1993b, p. 57), o que implica, de início, uma desconsideração do interesse próprio. $\mathrm{O}$ juízo reflexivo seria a única ou a principal capacidade do espírito a operar sob a pressuposição não apenas de que há um mundo, mas também de que não estamos sós nele.

A imaginação aproxima aquilo de que o juízo deve manter distância para ser imparcial. Essa distância significa um afastamento tanto do objeto (e de suas possíveis finalidades ou utilidades) como dos nossos interesses vitais, não para abandonar a mim mesmo ou ao objeto, mas simplesmente para deixá-lo ser. Tal movimento livre do olhar - 
Hannah Arendt usa o termo kantiano "alegria (ou satisfação) desinteressada" (uninteressiertes Wohlgefallen) (ARENDT, 1992, p. 263; cf. 1993b, p. 41) - só é possível quando se está liberado das necessidades vitais e se está livre para o mundo. Na verdade, tal distanciamento é mais propriamente uma condição da atividade do juízo que uma opção daquele que julga. A compreensão arendtiana do que se passa na vida da mente como atividades e ao mesmo tempo como uma retirada, mas não um desligamento, do mundo tal como é dado aos sentidos repousa em um pressuposto fundamental, o de que "todo ato espiritual repousa na faculdade do espírito ter presente para si o que se encontra ausente dos sentidos" (ARENDT, 1995, p. 60, grifos do autor). De qualquer modo, ainda que não seja possível uma desvinculação total das condições existenciais, na vida da mente, Hannah Arendt crê que ainda que condicionados existencialmente, os homens podem transcender as suas condições existenciais. É em vista disto que ela assume como herança de Kant o papel mediador da imaginação na relação da mente com o mundo.

Quando lida com as propriedades do juízo reflexivo estético, tal como aparece na terceira crítica, e trata de explicitar suas afinidades com a esfera política ou o caráter potencialmente político de sua operação, Hannah Arendt concebe a capacidade de imaginar não apenas como o tornar presente no espírito em imagens os objetos que não estão mais presentes, mas também como a capacidade de representar na mente o ponto de vista de todos os outros que habitam o mundo, tornados então virtualmente presentes e tomados efetivamente em consideração na formulação do juízo. Para Kant, a máxima da faculdade de julgar é uma mentalidade alargada, ou seja, a capacidade de pensar no lugar dos demais espectadores, de abandonar as condições privadas subjetivas do juízo e assumir uma maneira de pensar que toma em conta o alargamento do espírito a ponto de aquele que julga ser capaz de colocar a si próprio entre parênteses, desconsiderar o interesse próprio, e buscar assumir um ponto de vista geral, que tome em conta o ponto de vista de todos os outros, não empaticamente, mas pela abstração das limitações do meu próprio juízo (KANT, 1993, p. 140-141 [§ 40, 159160]). Esta é, ademais, a condição mesma da imparcialidade, tal como a assume Hannah Arendt. Para ela, o pensamento crítico, ou seja, aquele 
que se expõe ao exame livre e aberto e não deixa sequer a si mesmo a salvo do seu poder cáustico, o pensamento que é eminentemente antiautoritário e aberto implica comunicabilidade, em suma, não pode se dar sem a imaginação. Por meio dela, saio em visita a pontos de vista outros e posso adquirir um ponto de vista geral (termo que ela prefere a "universal" para traduzir allgemein), intrinsecamente vinculado aos pontos de vista particulares percorridos: "pensar com mentalidade alargada significa treinar a própria imaginação para sair em visita" (ARENDT, 1993b, p. 57). É também tendo isto em vista que ela pode afirmar ser representativo o pensamento político, pelo fato de que formo uma opinião acerca de um tema levando em consideração diferentes pontos de vista, representando em minha mente as posições dos que estão ausentes. Isto não significa que representar seja uma questão de empatia ou de "contar os narizes" e aderir a uma maioria, mas que "o próprio processo de formação da opinião é determinado por aqueles em cujo lugar alguém pensa e utiliza sua própria mente" (ARENDT, 1992, p. 299), em um exercício desinteressado (liberado dos interesses privados) de imaginação. Assim como Kant afirma que a "mentalidade alargada" é mais uma maneira de pensar que o atributo de um espírito amplamente dotado, Hannah Arendt sustenta que quando penso do ponto de vista dos outros, mais do que ampliar os domínios de meu próprio espírito, alargo minha própria perspectiva, em sua capacidade máxima de ser imparcial, e "a autêntica qualidade de uma opinião, como de um julgamento, depende do seu grau de imparcialidade" (ARENDT, 1992, p. 300; cf. KANT, 1993, p. 141 [§ 40, 159]).

Os juízos de gosto, distintamente dos juízos de conhecimento, não possuem um princípio objetivo determinado, pois, desse modo, poderiam reivindicar necessidade incondicionada para o seu juízo; no entanto, não podem ser desprovidos de todo e qualquer princípio, porque em tal condição não poderia requerer necessidade alguma. Assim, observa Kant, eles têm que possuir um princípio objetivo cuja função seja determinar a caracterização básica do que apraz e do que não apraz. Tal princípio só poderia ser considerado como um sentido comum (sensus communis) a partir do qual a operação do julgamento passa a se dar segundo conceitos e não segundo sentimentos, embora habitualmente somente ao 
modo de princípios obscuramente representados. Para Kant, "somente sob a pressuposição de que exista um sentido comum (pelo qual, porém, não entendemos nenhum sentido externo, mas o efeito decorrente do jogo livre de nossas faculdades de conhecimento)... o juízo de gosto pode ser proferido" (KANT, 1993, p. 83 [§ 20, 64]).

O senso comum consiste na garantia obscura, mas efetiva, contra as possíveis idiossincrasias intrínsecas a um juízo tão profundamente aderido à subjetividade quanto o juízo de gosto. A comunicabilidade universal de um sentimento, observa Kant, pressupõe um sentido comum, de modo que este deve ser admitido, não apoiado em observações psicológicas, "mas como a condição necessária da comunicabilidade universal de nosso conhecimento, a qual tem que ser pressuposta em toda lógica e em todo princípio dos conhecimentos que não seja cético" (KANT, 1993, p. 84 [§ 21, 66]).

A definição fundamental do juízo já havia sido dada na Crítica da razão pura: a faculdade de julgar seria a capacidade de subsumir sob regras, isto é, de avaliar se algo se encontra subordinado a uma regra ou não; isto corresponderia à formação no entendimento de uma unidade não dada no múltiplo da intuição: "se o entendimento em geral é definido como a faculdade das regras, então a capacidade de julgar é a faculdade de subsumir sob regras" (KANT, 1987, p. 98 [B171-172]). Mas a terceira Crítica não trata do juízo nessa sua forma, por assim dizer, mais estável. Ela lida com o juízo em suas duas formas mais voláteis: o juízo de gosto, que exige concordância universal sem poder cumprir objetivamente esta exigência; e o juízo teleológico, que mostra que as afirmações teleológicas sobre a natureza só podem ter uma função heurística, mas não objetiva. Esses juízos tendenciais são juízos praticamente sem regra de subsunção. Eles se orientam, antes de tudo, pela reflexão, isto é, pela capacidade ou habilidade de comparar e manter juntas dadas representações umas com as outras ou com a própria faculdade do conhecimento, em referência a um contexto tornado possível a partir disso. Dito de outro modo, é a reflexão que pressupõe uma adequação "sistemática" dos objetos ao nosso julgamento, que consegue captar uma uniformidade na multiplicidade dos eventos e das leis empíricas, como se nós as percebêssemos como sendo de antemão adequadas a serem apreendidas por nós. 
A capacidade de julgar em geral decorre tanto do fato de ser uma faculdade de subsumir sob regras como da habilidade em discernir conexões num dado contexto, um talento particular que não pode ser ensinado, apenas exercitado (KANT, 1987, p. 98 [B172]). Nesse duplo caráter da capacidade de julgar, aparece a preocupação tanto com a justificação quanto com a aplicação das regras, aliando uma compreensão do universal in abstracto a uma compreensão do particular in concreto. Desse modo, além da capacidade de interiorizar regras, no juízo joga importante papel também o "treinamento" da própria capacidade natural de julgar a partir de exemplos e atividades concretas. Os exemplos - embora no que se refira estritamente ao entendimento representem uma limitação para o esforço de compreensão das regras em geral e independente das circunstâncias particulares da experiência - aguçam a capacidade de julgar, são o seu andador [Gängelband], "o qual jamais pode ser dispensado por aquele ao qual falte talento natural para tal capacidade" (KANT, 1987, p. 98-99 [B173]).

O que tornaria o juízo, em seu modo reflexivo, tão fundamental aos nossos tempos e à reflexão sobre a política, na opinião de Hannah Arendt, seria todas essas suas características anteriormente mencionadas, mas fundamentalmente a sua capacidade de pensar o particular em sua dignidade própria. E isto não apenas pelo que mencionamos em epígrafe, mas ainda porque não podemos supor no coração ou na razão dos homens uma capacidade especial para distinguir o certo do errado e, no escopo do deslocamento do juízo estético kantiano para o âmbito prático, principalmente pela seguinte razão:

desde que a totalidade da sociedade respeitável sucumbiu a Hitler de uma forma ou de outra, as máximas morais que determinam o comportamento social e os mandamentos religiosos - 'Não matarás!' que guiam a consciência virtualmente desapareceram. Os poucos ainda capazes de distinguir o certo do errado guiavam-se apenas por seus próprios juízos, e com toda liberdade; não havia regras às quais se conformar, às quais se pudessem conformar os casos particulares com que se defrontavam. Tinham que decidir sobre cada caso quando ele surgia, porque não existiam regras para o inaudito (ARENDT, 1999, p. 318). 


\section{Referências}

AGUIAR, O. Filosofia, política e ética em Hannah Arendt. Ijuí: Ed. UNIJUÍ, 2009.

ARENDT, H. A crise na cultura: sua importância social e política. In: ARENDT, H. Entre o passado e o futuro. Tradução de Mauro W. Barbosa de Almeida. 3. ed. São Paulo: Perspectiva, 1992. p. 248-281.

ARENDT, H. Compreensão e política. In: ARENDT, H. A dignidade da política. 2. ed. Organização de Antônio Abranches. Tradução de Helena Martins e outros. Rio de Janeiro: Relume Dumará, 1993a. p. 39-53.

ARENDT, H. Lições sobre a filosofia política de Kant. Tradução de André Duarte. Rio de Janeiro: Relume Dumará, 1993b.

ARENDT, H. Hannah Arendt-Karl Jaspers correspondence. Tradução de Robert e Rita Kimber. Nova York: Harcourt Brace \& Company, 1993c.

ARENDT, H. A vida do espírito. Tradução de Antonio Abranches e Helena Martins. 3. ed. Rio de Janeiro: Relume Dumará, 1995.

ARENDT, H. O que é política? Tradução de Reinaldo Guarany. Rio de Janeiro: Bertrand Brasil, 1998.

ARENDT, H. Eichmann em Jerusalém. Tradução de José Rubens Siqueira. São Paulo: Companhia das Letras, 1999.

ARENDT, H. A condição humana. Tradução de Roberto Raposo e apresentação de Adriano Correia. 11. ed. Rio de Janeiro: Forense Universitária, 2010.

DUARTE, A. O pensamento à sombra da ruptura. Rio de Janeiro: Paz e Terra, 2000.

KANT, I. Crítica da razão pura. Tradução de Valério Rohden e Udo Baldur Moosburger. 3. ed. São Paulo: Nova Cultural, 1987. 
KANT, I. Crítica da faculdade do juízo. Tradução de Valério Rohden e António Marques. Rio de Janeiro: Forense Universitária, 1993.

LEBRUN, G. Kant e o fim da metafísica. Tradução de Carlos A. R. de Moura. São Paulo: M. Fontes, 1993.

Recebido: 06/10/2011

Received: 10/06/2011

Aprovado: $18 / 02 / 2012$

Approved: 02/18/2012 